\title{
Phonological awareness and reading speed deficits in reading disabled Greek- speaking children
}

Article

Accepted Version

Constantinidou, M. and Stainthorp, R. W. (2009) Phonological awareness and reading speed deficits in reading disabled Greek-speaking children. Educational Psychology, 29 (2). pp. 171-186. ISSN 0144-3410 doi:

https://doi.org/10.1080/01443410802613483 Available at https://centaur.reading.ac.uk/15719/

It is advisable to refer to the publisher's version if you intend to cite from the work. See Guidance on citing.

To link to this article DOI: http://dx.doi.org/10.1080/01443410802613483

Publisher: Taylor \& Francis

Publisher statement: This is an electronic author's postprint version of an article published in Educational Psychology Volume 29, Issue 2, 2009 see DOI: $10.1080 / 01443410802613483$

All outputs in CentAUR are protected by Intellectual Property Rights law, including copyright law. Copyright and IPR is retained by the creators or other copyright holders. Terms and conditions for use of this material are defined in the End User Agreement. 


\section{CentAUR}

Central Archive at the University of Reading

Reading's research outputs online 
Phonological awareness and reading speed deficits in reading disabled Greek speaking children

\title{
Maria Constantinidou and Rhona Stainthorp
}

\begin{abstract}
$\underline{\text { Abstract }}$
There is evidence that phonological awareness skills secure decoding ability and that phonological deficits underlie failure to acquire adequate word recognition. Slow word reading rate may be an additional defining characteristic of reading disability. The present study aimed to investigate whether: (1) reading disabled (RD) Greek-speaking children showed reading accuracy and reading speed deficits relative to chronological age matched (CAC) and reading age matched controls (RAC); (2) they showed phonological deficits relative to the two control groups who do not present reading difficulties, (3) they showed reading comprehension deficits over and above any word reading deficits.

Results suggested that the reading accuracy of the RD group was predictably weaker than that of the CAC group but equivalent to that of the RAC group. However, the reading speed of the RD group was significantly slower than the RAC group who showed the same single word reading speed as the CAC group.

Slow and laboured decoding was found to compromise the reading comprehension of the RD group whose listening comprehension performance was as good as the two other groups. The RD children performed poorly on phonological awareness tasks and naming speed. Naming speed was not an independent core feature of reading difficulties in the Greek language but was associated with a general phonological deficit.

It is recommend that diagnostic assessments for children with reading difficulties in Greek should include phonological awareness, single word reading and pseudoword reading tasks that measure both accuracy and speed.
\end{abstract}

Keywords: Dyslexia; Greek language; word reading speed; rapid automatized naming; phonological processes; reading comprehension. 


\section{$\underline{\text { Introduction }}$}

Probably no other skill taught in schools is more important than reading. It is the gateway to all other knowledge. If children fail to acquire this skill efficiently the path may be blocked to every other subject of the school curriculum and even beyond that since their life chances are likely to be negatively affected.

Word identification or word decoding is a primary and necessary condition for reading because fluent comprehension of texts would be almost impossible without it (LaBerge \& Samuels, 1974, Perfetti, 1985). However, in recent years it has emerged that accurate decoding is not the only condition necessary for skilled reading. The speed and accuracy at which single words are identified is the best predictor of comprehension. Slow word reading speed may compromise comprehension (Samuel, 1974; Perfetti and Hogaboam, 1975; Perfetti \& Lesgold, 1977; Perfetti 1985). Words should be effortlessly identified so that word reading takes up a minimal amount of processing capacity leaving as much as possible for understanding the texts (Bowers \& Wolf, 1993; Campton \& Carlisle 1994; Metsala \& Ehri, 1998; Joshi \& Aaron, 2002). Readers who constantly have to switch between the process of comprehension of the text and the identification of individual words to build up a mental model because their word identification is laboured will have greater difficulty understanding a text than those who decode swiftly and automatically and can concentrate on understanding the text as a whole.

Wood, Flowers and Grigorenko (2001) emphasize that fluency involves anticipation of what will come next in the text and that speeded practice alone is not sufficient. Anticipation facilitates reaction time and is particularly important for comprehension

According to Wolf and Katzir-Cohen (2001) 'In its beginnings, reading fluency is the product of the initial development of accuracy and the subsequent development of automaticity in underlying sublexical 
processes, lexical processes, and their integration in single-word reading and connected text. These include perceptual, phonological, orthographic, and morphological processes at the letter-, letter-pattern, and wordlevel; as well as semantic and syntactic processes at the word-level and connected-text level. After it is fully developed, reading fluency refers to a level of accuracy and rate, where decoding is relatively effortless; where oral reading is smooth and accurate with correct prosody; and where attention can be allocated to comprehension.' (Wolf \& Katzir-Cohen, 2001, p. 219). Thaler, Ebner, Wimmer and Landerl (2004) report that readers who achieve high level of accuracy but remain dysfluent fail to build up orthographic representations because they activate the necessary association between graphemes and phonemes too slowly and this makes an efficient amalgamation of the phonological and the orthographic word form impossible.

There is evidence that slow word reading rate is a defining characteristic of reading disabled children (Campton \& Carlisle, 1994), particularly in transparent orthographies. Participants with developmental dyslexia perform significantly slower and less accurately than controls on reading tasks (King, Lombardino \& Ahmed, 2005; Tressoldi, Lorusso, Brenbati \& Donini, 2007; Wimmer, 1993; Wimmer \& Goswami, 1994,). Snowling (2000) suggests that this association problem could occur as a consequence of a slow and inefficient phonological lexicon.

Substantial efforts have been directed towards understanding the cause of word reading difficulties. The dominant explanation is the phonological deficit hypothesis. According to this hypothesis individuals with reading difficulties have problems with their underlying phonological representations, which affect performance on any task that requires phonological processing. A phonological awareness deficit underlies the failure to acquire adequate word recognition skills (Bradley \& Bryant, 1983; Stanovich, 1986; Blachman, 1997, Goswami 2000; Snowling, 2000, 2002) and has been identified as the primary deficit compromising efficient 
word reading skills (Bradley \& Bryant 1983; Stanovich, 1986; Blachman, 1997; Goswami 2000; Snowling, 2000, 2002).

When the phonological deficit is investigated, studies have used tasks, which directly assess ability to be aware of and to manipulate the sounds in words (e.g. Yopp, 1988) and also tasks, which assess ability to name familiar items as rapidly as possible (e.g. Torgesen, Wagner, et al., 1997). Denckla and Rudel $(1974,1976)$ first demonstrated a strong relationship between children's performance on Rapid Automatised Naming (RAN) tasks and their reading development. Wagner, Torgesen and colleagues (Wagner \& Torgesen, 1987; Wagner, Torgesen, et al., 1997) emphasise the fact that a fundamental shared component of both RAN and reading itself is phonological processing. They propose that RAN tasks index the retrieval speed of phonological information from memory and are thus best described as an aspect of phonological processing. This is consistent with the phonological core deficit theory of developmental dyslexia (Hulme \& Snowling, 1992; Snowling, 2000; Stanovich \& Siegel, 1994). However, Wolf and Bowers (e.g., Bowers \& Wolf, 1993; Wolf \& Bowers, 1999) argue that RAN tasks index processes that are at least in part independent of phonology and this view finds support in correlational studies showing that early RAN performance accounts for a significant unique proportion of the variance in both concurrent and future reading measures independent of measures of PA (e.g., Ackerman \& Dykman, 1993; Badian, 1993; Manis, Seidenberg, \& Doi, and in a recent experimental study Powell, Stainthorp et al. (2007). Wolf and Bowers suggest that though some dyslexic children have a major problem with phonological awareness, others may have a processing deficit that is indexed by RAN and that a further more compromised group of children may show a double deficit. 
The majority of the research referenced above relates to studies of reading and reading difficulties in English, which has a notoriously complex, opaque orthography. However, research on reading acquisition based on one orthographic system may not account for performance in all languages. The behavioural manifestations of reading difficulties are strongly influenced by the orthography of the language (Frith, 2001; Goulandris, 2003; Ziegler \& Goswami, 2005; Ziegler et al 2003). Research in transparent orthographies (Goswami, 2000; Goswami, Porpodas, \& Wheelwright, 1997; Wimmer, 1993; Wimmer \& Goswami, 1994) supports the view that differences in the orthographic structure of languages have an effect on children's literacy development. A consequence of this is that reading disabled children learning to read in a transparent orthography present different patterns of performance when compared to reading disabled children learning to read in opaque orthographies such as English. Studies in different transparent orthographies indicate that deficits in phonological awareness is a universal feature of reading difficulties and that phonological awareness is very important to reading (Goulandris, 2003). Evidence comes from Dutch (de Jong 2003), Finnish (Puolakako et al., 2004), Spanish (Jimenez Gonzalez, Alvarez Gonzalez, Estevez Monzo, \& Hernadez-Valle, 2000), Greek (Porpodas, 1999; Nikolopoulos et al., 2003). There is evidence however that certain phonological awareness tasks are easier for reading disabled children learning to read a transparent orthography than children learning to read English (Ziegler \& Goswami, 2003).

The current study aimed to provide further evidence relating to reading difficulties in a transparent language: Greek. Unlike English, Greek is considered to have a shallow, transparent orthography. The phonological structure of the majority of words is transparent since in most cases each grapheme is represented by one phoneme. There are some inconsistencies in the case of vowels for spelling with some phonemes being represented by more than one grapheme (/i/ is 
written using the letters $1, \eta, v$ and the letter combinations $\varepsilon 1,01, v 1 .$. In the same way the phoneme /e/ is written with the letter $\varepsilon$ and the letter combination $\alpha$. This is more of a challenge for spelling than reading.

The reason for this degree of inconsistency is because the language used today is thought to reflect the phonetic etymology of words rather than their phonological identity (Porpodas, 1990; Triantaphylides, 1913). The spoken form of Modern Greek has undergone evolutionary and developmental changes whereas the spelling of the Greek language remained the same since antiquity and it lost some of its phonetic character. Nevertheless, relative to English which has up to now been the most researched language, Greek has a high degree of transparency. There are not many studies investigating the area of reading difficulties in Greek.

The present study is an investigation into the reading difficulties of Greek speaking Cypriot children learning to read Greek. The aim of the present study was to provide further clarification of possible phonological processes deficits found in children with reading problems in the Greek language. It further aimed to investigate whether poor word reading speed was an additional characteristic. To probe this issue further, pseudoword reading accuracy and speed was also measured. Pseudoword reading is a purer measure of decoding ability compared to reading word lists and it is essential for progress in reading (Share, 1995). Additionally it aimed to investigate whether word reading speed accounted for a significant amount of the variance in reading comprehension.

\section{Method}




\section{$\underline{\text { Participants }}$}

Three groups of 20 children each $(\mathrm{N}=60)$ participated in this study. They all attended schools in different towns in Cyprus. The first group consisted of children who had been identified by a multidisciplinary team as having reading difficulties. This team was composed of educational psychologists, speech therapists and teachers with advanced special education qualifications. All children met the same diagnostic criteria: a history of reading and spelling problems and a discrepancy between reading and other cognitive abilities. All children were receiving extra help on their reading and writing by special education teachers. Their ages ranged from 9 years 6 months to 9 years 11 months. This group will be referred as the reading disabled (RD) group. Two further groups were identified to act as controls: (1) A chronological age controlled group (CAC), which was matched on chronological age but with no reported reading difficulties and age appropriate reading levels as reported by their teachers; and (2) a reading age control group (RAC), which was matched on the reading age of the RD group relative to their respective performance in school. Accuracy scores on the initial trialing of the word identification test were used to identify the RAC group. Group means were used to achieve matching of the two groups. The RAC control group was inevitably younger with ages ranging from 6 years 9 months to 6 years 11 months, and had received less schooling than the two other groups. None of the children in the RAC group were reported to have reading difficulties and were all identified by their teachers as reading age appropriately. All children were monolingual speakers of Greek, they all came from similar socio-economic backgrounds and they were all matched on IQ scores. Ravens coloured progressive matrices were administered. This is a standardised measure of nonverbal ability. The mean (and standard deviation) score for the RD group was 77.50 (12.19);

for the RAC group it was 78.00 (12.18) and for the CAC group it was 77.75 (13.69). The data 
were analysed using a one way ANOVA. This showed no difference between the groups, $\underline{\mathrm{F}}$ $(2.57)=.049, \underline{p}=.95$.

\section{Procedure and measures}

All participants were assessed individually by the first author in a quiet room in their schools. The project was passed by the ethics committee of the School of Psychology and Human Development at the Institute of Education, University of London and agreed by the Ministry of Education in Cyprus. The children were informed that they could stop participating at any time.

\section{$\underline{\text { Reading tasks }}$}

$\underline{\text { Word reading }}$

Due to the lack of suitable standardised tests for assessing word reading skills among Greek speaking Cypriot students, an experimental word reading accuracy test was developed. This consisted of words, which varied in length from two to five syllables. Syllable complexity was manipulated with items containing CVs, CCVs or CCCVs . There is as yet no reliable frequency database in Greek therefore all words came from the reading textbooks used in primary schools. After initial trailing of items 60 words were chosen. Cronbach's alpha for the test as a whole was .918 (.738 for CV items; .742 for CCV items; and .759 for CCCV items). A correct reading was considered to be the one with correct pronunciation and the correct use of the stress. The reading accuracy score was found by adding up the number of correctly read words. The data gathered were coded as the percentage of correct words read. The test items are included in Appendix 1.

Because word reading fluency was a variable of interest to the study, in addition to assessing word reading accuracy word reading speed was calculated at the same time. A 
stopwatch was used to log the time taken to read the stimuli. The data gathered were coded as the time in seconds children needed to read. Children were asked to read aloud as fast as possible without rushing in order to avoid mistakes.

\section{Pseudoword reading}

An experimental pseudoword reading test was developed which consisted of 60 pseudowords which varied in length and syllable complexity in the same way as for the word reading test as described above. The pseudowords were created by manipulating syllables of real words to ensure orthographic legality. Cronbach's alpha for the test as a whole was .933 (.775 for CV items; .814 for CCV items; and .808 for CCCV items). The data gathered were coded as the percentage of correct words read. A correct reading was considered to be one where there was accurate pronunciation using letter-sound correspondences and the correct use of stress. Additionally, pesudoword reading speed was measured manually using a stop watch. The data gathered were coded as the time in seconds children needed to read. Children were asked to read aloud as fast as possible without rushing in order to avoid mistakes.

\section{Phonological awareness tasks}

The Phonological Assessment Battery (PhAB), (Frederickson, Frith \& Reason, 1997), was used as a model for the creation of a series of experimental phonological awareness tasks in Greek. Five tests of phonological processing were developed.

1) The alliteration test, which tapped specific ability to recognise the shared phonemes at the beginning of words. There were two forms of this test. The 
oral test and the picture test. A set of ten items was provided for each test. In the picture test pictures of the named objects were provided and the child could respond by pointing. Cronbach's alpha for the test as a whole was .468

2) The spoonerism test, which tapped ability to manipulate the phonemes in words. This was in two parts. Semi-Spoonerisms where the participants had to replace the initial sound in a given word with a specified phoneme and Full Spoonerisms where the participants had to switch the first phonemes of two given words. Each test consisted of 10 items. Cronbach's alpha for the test was .838

3) The rhyme test, which was designed to assess phonological awareness at the level of sub-syllabic unit of rime. On each trial children had to listen to three words and say which two of the three ended with the same sound. The test consisted of 21 items. Cronbach's alpha for the test was .930

4) The fluency test designed to assess ability to locate words in the lexicon using phonemic cues. Participants had to generate words beginning with the sound $/ \mathrm{k} /$ and the sounds $/ \mathrm{m} /$. They were asked to give as many words as they could in 30 seconds Cronbach's alpha for the test was .845

5) Rapid automatised naming (RAN), which determined how readily children could name random sequences of digits. Cronbach's alpha for the test was .570

\section{Comprehension}

An experimental Greek comprehension test was produced following the guidelines of the Individual Reading Analysis test, (Vincent \& De la Mare, 1992). All passages of the test were 
translated into Greek and the same pictures were used. The IRA contains three sets of 5 graded passages designed to be alternate forms. Cronbach's alpha for the test was .341. After reading each passage in a set out aloud the children are asked a series of comprehension questions which they have to answer orally.

Two weeks after the reading comprehension test was administered the children listen to a further set of five passages from the translated set. As with the reading comprehension test, after each passage was read to the participants they were asked a series of questions which they answered orally.

The reading and listening comprehension score was computed by adding up the number of correctly answered questions. The data gathered were coded as the percentage of correct answers given.

All experimental measures were initially piloted on children in mainstream classes.

\section{$\underline{\text { Results }}$}

\section{$\underline{\text { Reading ability }}$}

Table 1 shows the mean percentage accuracy scores for word and pseudoword reading by each group.

\section{<Table 1 here>}

In order to investigate the general reading accuracy performance of the three groups a one-way ANOVA was conducted on the percentage of the total scores of each group. There was a significant main effect of groups $\underline{F}(1,57)=414.84 ; \underline{p}<.001$; with large effect size $\left(\eta^{2}=.16\right)$. Post Hoc comparisons using Bonferroni's correction revealed no difference in the performance of the RD and RAC groups $(\mathrm{p}=.87)$ both these groups had significantly lower levels of accuracy than the CAC group. The equivalence of the word reading accuracy of the RD and RAC groups 
served to confirm the initial selection of the RAC group as reading at the school level equivalent of the RD group

Pseudoword reading accuracy was investigated using a one-way ANOVA on the percentage of the total scores for each group. This showed that there was an overall group effect on pseudoword reading accuracy, $\underline{\mathrm{F}}(1,57)=562.18 ; \underline{\mathrm{p}}<0.001 ; \eta^{2}=0.95$, suggesting a very large effect size. The group comparisons using Bonferroni's correction showed that there was no difference in performance between the RD and the RAC groups and that both these groups had significantly lower level of accuracy than the CAC. Thus, the same pattern of results as in the case of word reading accuracy are also revealed when looking at the performance of each group on pseudoword reading accuracy.

Group differences in word reading speed were investigated using one-way ANOVAs. The results revealed that there was an overall difference in the word reading speed performance between the groups, $\underline{\mathrm{F}}(2,57)=40.24 ; \mathrm{p}<.001 ; \eta^{2}=.59$. Post Hoc comparisons using Bonferroni's correction revealed no difference in the performance of the CAC and RAC groups and both these groups had significantly higher levels of reading speed than the RD group. Even though the RD group had the same reading accuracy as the RAC group they were significantly slower when reading than this group which were three years younger than them.

There was also a similar main effect of groups when reading the pseudoword, $\underline{\mathrm{F}}(2,57)=$ 17.16, $\mathrm{p}<0.001, \eta^{2}=.38$. Post Hoc comparisons using Bonferroni's correction revealed no difference in the performance of the CAC and RAC groups both these groups had significantly higher levels of reading speed than the $\mathrm{RD}$ group. 


\section{Phonological awareness ability}

Table 2 shows the means and standard deviation for children's accuracy on the phonological awareness tasks.

\section{$<$ Table 2 here>}

One-way ANOVAs were conducted to explore the performance of the three groups of children on each of the phonological awareness tasks. There was no significant main effect of groups for Alliteration (oral), $\underline{\mathrm{F}}(2,57)=3.059 ; \underline{\mathrm{p}}=0.06$, and Alliteration (picture), $\underline{\mathrm{F}}(2,57)=$ $2.803 ; \underline{p}=0.07$. Bonferroni's correction indicated that there was no difference in the performance of the RD children compared to the performance of the two groups of children on the oral alliteration task or on the picture alliteration tasks. All the children were at or near ceiling on this task so the results of the analysis have to be treated with caution.

However, there was a main effect of groups on Rhyme task, $\underline{\mathrm{F}}(2,57)=20.47, \underline{\mathrm{p}}<0.001$. Bonferroni's correction indicated that there was a significant difference in the performance of the two groups of normal readers and the reading disabled group. The RD group was significantly less accurate than the other two groups. There was no significant difference in the performance of the two groups of normal readers.

There was also a main effect of groups for Semi-Spoonerisms, $\underline{F}(2,57)=6.64 ; \underline{p}<.001$, $=\eta^{2} .189$ and Full-Spoonerisms $\left.\underline{\mathrm{F}}(2,57)=90.01 ; \underline{\mathrm{p}}<.001, \eta^{2}=.76\right)$. Bonferroni's correction on the Semi-Spoonerism task indicated that the RD group was as accurate on this task as the RAC but less accurate that the CAC group. There was no difference between the two control groups. Bonferroni's correction for the Full-Spoonerisms task showed that the RD group was less accurate that the RAC and CAC groups whose performance was equivalent. 
There was a main effect of groups for the fluency alliteration tasks, $\underline{F}(2,57)=49.509 ; \underline{p}<$ $.001, \eta^{2}=.445$. Bonferroni's correction indicated that the RD group performed poorly on these tasks compared to the two groups of normal readers who again performed at the same level.

There was also a main effect of groups for the RAN task, $\underline{\mathrm{F}}(2,57)=64.025, \underline{\mathrm{p}}<.001, \eta^{2}$ $=.692$. Bonferroni's correction showed the RD group was significantly slower than the other two groups and there were no differences between the two control groups.

\section{$\underline{\text { Reading and phonological awareness }}$}

We used hierarchical multiple regression to investigate the relationship between phonological awareness and reading. A composite measure of phonological awareness using the scores for the two spoonerisms tasks, alliteration fluency and rhyming was computed. RAN was entered as a separate variable.

\section{<Table 3 here>}

Table 3 shows the summary of these regression analyses. For both word reading accuracy and fluency phonological awareness made a significant unique contribution to performance. However, RAN only made a contribution to word reading speed.

\section{Comprehension}

Table 4 shows the mean percentage performance by the three groups for both the reading and the listening comprehension tasks.

\section{<Table 4 here>}

A two-way repeated measures ANOVA was conducted to investigate the three group's reading and listening comprehension performance. There were three levels of the between groups factor and two levels of the within groups factor mode of input (reading and listening). There was a significant main effect of mode, $\left.\underline{\mathrm{F}}(1,57)=159.07 ; \underline{\mathrm{p}}<.001 ; \eta^{2}=0.74\right)$, a 
significant group effect, $\underline{\mathrm{F}}(2,57)=27.11 ; \underline{\mathrm{p}}<.001 ; \eta^{2}=0.48 ;$ and a significant interaction, $\underline{\mathrm{F}}$ $(2,57)=55.41 ; \underline{p}<.001 ; \eta^{2}=0.66$. This interaction was due to the RD group being significantly worse on reading comprehension than the other two groups. The main effect of groups and the effect of mode (listening and reading) were all accounted for by this reduction in comprehension performance

Hierarchical multiple regressions were used to investigate the contribution of RAN, phonological awareness, word reading accuracy and word reading speed on reading comprehension. Table 5 gives a summary of the analysis.

$<$ Table 5 here $>$

Though word reading accuracy made a significant contribution to reading comprehension when entered in step 1, this disappeared when phonological awareness was entered at step 2. Word reading accuracy, phonological awareness, RAN and word reading speed accounted for 56.7 per cent of the variance in reading comprehension. When all the variables were entered into the equation only word reading speed made a significant unique contribution to reading comprehension.

\section{$\underline{\text { Discussion }}$}

The overall results suggest that the behavioural manifestations of dyslexia are strongly influenced by the orthography of the language (Frith, 2001; Goulandris, 2003; Ziegler and Goswami, 2005). In a transparent orthography like the Greek language the amount of variability in word reading accuracy between reading disabled children and normal readers is reduced because of the consistency of the language. The identification of the RD group as having reading problems was confirmed. The RD children were less accurate than their chronological age classmates but as accurate as the group of younger children with the same reading age. The 
results also revealed that typical Greek speaking children managed to reach virtual ceiling performance by the end of their ninth year and this is probably due to the transparent orthography where grapheme-phoneme correspondences are consistent. The word and pseudoword reading results showed that the RD children were particularly poor at reading quickly. This indicates that their decoding skills were compromised relative to reading age controls. Though they could read items as accurately, they had not automated their decoding skills. The results showed, as predicted that this lower word reading efficiency had a significant effect on their ability to comprehend texts. Though, when listening, their language comprehension was as good as normal readers, their lack of fluent word reading led to a reduction in text comprehension when reading. The results also address issues relating to the contribution of RAN to word reading.

The decoding skills of the RD group were equivalent to those of the young reading age controls. This adds further evidence to the view (Wimmer, 1993, 1994) that when children are required to read in a transparent orthography, they are able to overcome possible decoding problems sufficiently to enable them to make some progress even when reading unknown items like pseudowords. However, the speed data show that their word reading skills are compromised by inefficient decoding. We interpret this as suggesting that the children identified as having reading difficulties were able to map the letter sound correspondences and so apply this knowledge to identifying the phonology of written words or pseudowords. However, this mapping had not yet reached a level of automaticity where the items were read fluently. This was in clear contrast to the younger reading age control children who had reached the same level of automaticity as the older normal readers, but who made the same number of errors as the RD children. For these younger readers there was obviously a speed accuracy trade off. 
Though the RD group were as good as the control groups when performing alliteration tasks, they showed phonological deficits when faced with the more demanding spoonerisms tasks. These data indicate that this group of children who were identified as having reading problems showed similar characteristics to dyslexic children learning to read English in that they had a measurable phonological deficit. The RD group also showed poorer performance on the RAN task.

The hierarchical regression analyses showed that Greek is no exception when one considers the contribution that phonological awareness makes to word reading. However, there was some evidence in support of the double deficit view of dyslexia because though phonological awareness made a significant unique contribution to accuracy, RAN did not. RAN appeared to be only important in terms of word reading speed.

These data suggest that when seeking to identify children with reading difficulties in Greek such as these children in Cyprus it is important to assess both accuracy and speed of word and pseudoword reading and to differentiate between phonological awareness and rapid naming. If only accuracy data is considered, a child may be considered to be a garden variety poor reader (Stanovich, 1988) but the profile of poor word reading speed, and compromised phoneme awareness and naming speed may suggest a child with a specific learning difficulty. These results may suggest that the RD children may have a phonological deficit in that the phonological representations (mental representations of word pronunciation) are less accessible to them and it takes longer to access them. It is obvious that they were able to access phonological representations since they were just as accurate in decoding as the RAC group however they were slower, which indicates that speed indeed is an important factor that needs to be taken into consideration. This finding replicates recent studies conducted in transparent 
orthographies (Goswami, 2000; Wimmer, 1993, 1996, 1997; Ziegler et al, 2003) which stress the importance of a speed deficit and especially a pseudoword decoding speed deficit that affects dyslexics.

The RD children participating in this study were not as accurate as the reading disabled children reported in Wimmer $(1993,1996)$. However their patterns of performance were similar. There were no reading refusals and no real word responses to pseudowords. The errors were minor deviations from the correct pronunciations. As Ellis et al. (2004) indicate this pattern of errors is generally observed in learners of transparent orthographies.

The results from this study reflect findings from studying the performance of German speaking children (Landerl, Wimmer \& Frith, 1997; Wimmer, 1993) and show that a phonological awareness deficit is also marked in dyslexics learning a transparent language, but phonological awareness performance levels reflect different task demands. The reading disabled children in this study were over 9 years old and the data suggest that simple tasks of alliteration are not sensitive enough to identify weaknesses. However, the more challenging Spoonerisms task was able to discriminate between the groups very successfully.

Different studies (Landerl \& Wimmer, 2000, Morris et al., 1998; Pennington et al., 2001) indicate that in transparent languages slowness in naming is one of the key markers of dyslexia and not phonological awareness problems in general. Morris et al., (1998) and Pennington et al., (2001) support that reading disabled children with a deficit in rapid serial naming were relatively more impaired in fluency of text reading. The results of this study showed that the reading disabled children performed significantly slower than normal readers on the RAN task.

Given that reading speed seemed to be such an important deficit for the reading disabled children. The finding that this was the unique predictor of individual differences in 
comprehension has major implications. The "bottleneck" hypothesis, originally proposed by Broadbent (1958) has been used to explain reading comprehension difficulties as they related to speed of decoding (Treisman, 1960; Deutsch \& Deutsch, 1963; Perfetti \& Lesgold, 1977). According to this theory word decoding processes and comprehension processes compete for a space in the short term memory. Therefore in the case of poor readers, slow and less automatic decoding creates a "bottleneck" in working memory leaving less functional capacity available to them for comprehension processes. As a result it is possible that an earlier part of a sentence may no longer be available in the working memory when the final part has been decoded and can't be integrated with the earlier part.

The results of this study are in line with the "bottleneck" theory. Automating of word identification leads to fewer demands on the higher-order linguistic skills (grammatical and semantic processes), which are important for comprehension. Lack of automation means that more mental work is needed for word identification leaving less capacity available at any one time for comprehension.

Overall we can conclude that dyslexia in the Greek language is caused by a deficit in phonological processing which leads to the predictable poor level of word reading. However reading speed is differentially affected and this adds to the poorer level of reading comprehension. If word identification processes were automatic then the meaning of the text would be processed more quickly. This finding needs further investigation using different sets of stimuli in order to establish exactly which reading processes failed to become automatic: the sublexical processes or lexicalised recoding. It would be interesting to address the issue of analogy to identify whether reading speed as well as accuracy is affected by the use of analogy in the Greek language 
Furthermore, it would have been helpful to investigate how word familiarity effects could influence response time for reading words and can have an influence on the word recognition processes. There is a need for a Greek corpus of printed words from children's reading books such as that developed by Masterson, Stuart, Dixon \& Lovejoy (2003) for English.

\section{Educational implications}

It is clearly evident that reading speed is an issue that needs to be taken into consideration when considering transparent orthographies. The results of the present study highlight the importance of including reading speed measures in diagnostic and prediction test batteries. Speed as well as accuracy should be included in the criteria for detecting reading problems. Testing on reading accuracy alone, or even testing accuracy on certain phonological tasks may leave some children undetected since the transparency of the orthography facilitates reading accuracy performance and performance on certain phonological awareness tasks.

A central issue in this study was the reading disabled children's failure to achieve automaticity in reading. Given this, future research is needed to begin to ask how to design interventions that will enable children to develop automaticity in the underlying phonological skills and the decoding skills that contribute to reading fluency. At the moment intervention activities designed to help Greek-speaking children to overcome their phonological problems as well as reading problems place an emphasis on accuracy.

The results of this study clearly suggest that any intervention activities should stress both accuracy and speed in reading outcomes in each component skill i.e. letter recognition and plausible auditory discrimination of phonemes, decoding etc. At this point it would be useful to indicate that future research on the role of phonological awareness in reading could use 
phonological awareness response time tasks. Speed of response on phonological awareness measures could further clarify the role of phonological awareness in reading difficulties in transparent orthographies.

\section{$\underline{\text { References }}$}

Ackerman, P. T., \& Dykman, R. A. (1993). Phonological processes, confrontation naming, and immediate memory in dyslexia. Journal of Learning Disabilities, 26, 597-609.

Badian, N. A. (1993). Phonemic awareness, naming, visual symbol processing, and reading. Reading and Writing: An interdisciplinary Journal, 5, 87-100.

Bowers, P. G., \& Swanson, L.B. (1991). Naming speed deficits in reading disability: Multiple measures of a singular process. Journal of Experimental Child Psychology, 51, 195219.

Bowers, P.G., \& Wolf, M. (1993). Theoretical links among naming speed, precise timing mechanisms and orthographic skill in dyslexia. Reading and Writing: An Interdisciplinary Journal, 5, $69-85$.

Blachman, B. (1997). Foundations of reading acquisition and dyslexia. London: Lawrence Erlbaum Associates.

Bradley, L., \& Bryant, P. E. (1983). Categorising sounds and learning to read: A causal connection. Nature, 301,_419-521.

Broadbent, D. E. (1957). A mechanical model for human attention and immediate memory. Psychological Review, 64, 205-215.

Broadbent, D. E. (1958). Perception and communication. New York: Pergamon. 
Compton, D. L., \& Carlisle, J. (1994). Speed of word recognition as a distinguishing characteristic of reading disabilities. Educational Psychology Review, 6, 115 - 140.

de Jong, P.F (2003). Problems in the acquisition of fluent word decoding in Dutch children. In N. Goulandris (Ed), Dyslexia in different languages: Cross-linguistic comparisons. (pp33-52). London: Whurr.

Denckla, M. B., \& Rudel, R. G. (1974). Rapid “automatized” naming of pictured objects, colours, letters, and number by normal children. Cortex, 10, 186-202.

Denckla, M. B., \& Rudel, R. G. (1976). Rapid “automatized” naming (RAN): Dyslexia differentiated from other learning disabilities. Neuropsychologia, 14, 471-479.

Deutsch, J. A., \& Deutsch, D. (1963). Attention: some theoretical considerations. Psychological Review, 70, 80-90.

Ellis, N. C., Natsume, M., Stavropoulou, K., Hoxhallari, L., Van Daal, V. H.P., Polyzoe, N., Tsipa, M., \& Petalas, M. (2004). The effects of orthographic depth on learning to read alphabetic, syllabic, and logographic scripts. Reading Research Quarterly, 39, 438-468.

Frederickson, N., Reason, R., Frith, U., Gallagher, A., Forrester, A., Gibbs, S., Miller, A., Wilson, J., Cline, T., Bunn, T., Walton, D., Wilson, J. (1995). Phonological assessment of specific learning difficulties. Educational and Child Psychology, 12, 1-88.

Frith , U. (2001). What framework should we use for understanding developmental disorders. Developmental Neuropshychology, 20, 555-563.

Goswami, U. (2000). Phonological representations, reading development and dyslexia: Towards a cross-linguistic theoretical framework. Dyslexia, 6, $124-132$. 
Goswami, U., Porpodas, C., \& Wheelwright, S. (1997). Children's orthographic representations in English and Greek. European Journal of Psychology of Education, XII, 273 292.

Goulandris, N. (2003). Dyslexia in different languages: Cross-linguistic comparisons. Philadelphia: Whurr.

Hulme, C., \& Snowling, M. (1992). Deficits in output phonology: an explanation of reading failure. Cognitive Neuropsychology, 9, 42-72.

Jimenez Gonzalez, J.E., Alvarez Gonzalez, C,J., Estevez Monzo, A., \& Hernadez-Valle, I (2000). Onset-rime units in visual word recognition in Spanish normal readers and children with learning disabilities. Learning Disabilities Research and Practice, 15, 135-141.

Joshi, M., \& Aaron, P. (2002). Naming speed and word familiarity as confounding factors in decoding. Journal of Research in Reading, 25, $160-171$.

King, W.M., Lombardino, L.L., \& Ahmed, S. (2005) Accuracy and speed of orthographic processing in persons with developmental dyslexia. Perceptual and Motor Skills 101, 95-107.

Landerl, K., \& Wimmer, H. (2000). Deficits in phoneme segmentation are not the core problem of dyslexia: evidence from German and English children. Applied_Psycholinguistics, 21, 243- 262.

Landerl, K., Wimmer, H., \& Frith, U. (1997). The impact of orthographic consistency on dyslexia: A German-English comparison. Cognition 63, 315-334.

La Berge,D., \& Samuels, S.J. (1974). Towards a theory of automatic processing in reading. Cognitive Psychology, 6, 293-323. 
Manis, F., Seidenberg, M., \& Doi, L. (1999). Rapid naming and the longitudinal prediction of reading subskills in first and second graders. Scientific Studies of Reading, 3, 129 157.

Masterson, J., Stuart, M., Dixon, M., \& Loverjoy, S. (2003). Children's printed word database. ESRC research project.

Metsala, I. L., \& Ehri, L.C. (1998). Word recognition in beginning literacy. Mahwah, NJ: Lawrence Erlbaum Associates.

Morris, R., Stuebing, K., Fletcher, J., Shaywitz, S., Lyon, R., Shankweiler, D., Katz, L., Francis, D., \& Swaywitz, B. (1998). Subtypes of reading disability: A phonological core. Journal of Educational Psychology, 90, 347 - 373.

Pennington, B., Cardoso-Martins, C., Green, P., \& Lefly, D. (2001). Comparing phonological awareness and double deficit hypotheses for developmental dyslexia. Reading and Writing: An Interdisciplinary Journal, 14, 707-755.

Perfetti, C. A. (1985). Reading Ability. Oxford: Oxford University Press.

Perfetti, C. A., \& Hogaboam, T. (1975). Relationship between single word decoding and reading comprehension skill. Journal of Educational Psychology, 67, 461-469.

Perfetti, C.,A., \& Lesgold, A.M. (1977). Coding and comprehension in skilled reading and implications for reading instruction. In L.B. Resnick \& P.A. Weaver (Eds.), Theory and practice of early reading (Vol. 1, pp 57-84). Hillsdale, NJ: Erlbaum.

Porpodas, C. (1990). Processes used in children's reading and spelling Greek words. In G.T. Pavlidis (Ed.), Perspectives on dyslexia. New York: John Wiley \& Sons.

Porpodas, C. (1999). Patterns of phonological and memory processing in beginning readers and spellers of Greek. Journal of Learning Disabilities, 32, 406-416. 
Powell, D., Stainthorp, R., Stuart, M., Quinlan, P., \& Garwood, H. (2007). An experimental comparison between rival theories of Rapid Automatised Namind (RAN) performance and its relationship to reading. Journal of Experimental Child Psychology, 98, 4668.

Puolakanaho, A., Poikkeus, A-M., Ahonene, T., Tolvanen, A., \& Lyytinen, H. (2004). Emerging phonological awareness differentiates children with and without familial risk for dyslexia after controlling for general language skills. Annals of Dyslexia, 54, 221-243.

Samuels, S.J. (1979). The method of repeated reading. The Reading Teacher, 32 2 403408.

Share, D. L. (1995). Phonological recoding and self-teaching: Sine qua non of reading Acquisition. Cognition, 55, 151-218.

Snowling, M. (2000). Dyslexia. $2^{\text {nd }}$ Edition. Oxford: Blackwell.

Snowling, M., \& Frith, U. (1986). Comprehension in "Hyperlexic" readers. Journal of Experimental Child Psychology, 40,_392-413.

Stanovich, K. E. (1986). Mathew effects in reading: Some consequences of individual differences in the acquisition of literacy. Reading Research Quarterly 21, 360-406.

Stanovich K.E. (1988). Explaining the differences between dyslexic and garden-variety poor readers. The phonological-core variable-difference model. Journal of Learning Disabilities. $21,590-604$.

Stanovich, K. E., \& Siegel, L. (1994). The phenotypic performance profile of reading disabled children: A regression-based test of phonological-core variable-difference model. Journal of Educational Psychology, 86, 24-53. 
Thaler, V., Ebner, E., Wimmer, H., \& Landerl, K., (2004). Training reading fluency in dysfluent readers with high reading accuracy: word specific effects by low transfer to untrained words. Annals of Dyslexia, 54, $89-113$.

Torgesen, J.K., Wagner, R.K., Rashotte, C.A., Burgess, S., \& Hecht, S. (1997).

Contribution of phonological awareness and rapid automatic naming ability to the growth of word reading skills in second to fifth grade children. Scientific Studies of Reading, 12161-185.

Torgesen, J.K., Rashotte, C.A., \& Alexander, A.W. (2001). Principles of fluency instruction in reading: Relationships with established empirical outcomes. In M. Wolf (Ed.), Dyslexia, fluency, and the brain. Timonium, MD: York Press.

Treisman, A. M. (1960). Contextual cues in encoding listening. Quarterly Journal of Experimental Psychology, 12, 242-248.

Tressoldi, P.E., Lorusso, M.L., Brenbati, F., \& Donini, R., (2007). Fluency Remediation in Dyslexic Children: Does Age Make a Difference? Dyslexia 14, 142 - 152.

Triantaphylides, M. (1913). H O $\rho \theta 0 \gamma \rho \alpha \varphi i \alpha \mu \alpha \varsigma$, (Our Orthography)._Athens: Estia (in Greek).

Vincent, D. \& de la Mare, M. (1992). Individual reading analysis. Windsor: NFERNelson.

Wagner, R. K., \& Torgesen, J. K. (1987). The nature of phonological processing and its causal role in the acquisition of reading skills. Psychological Bulletin, 101, 192-212.

Wagner, R. K., \& Torgesen, J. K., Rashotte, C.A., Hecht, S.A., Barker, T.A., Burgess, S.R., Donahue, J., \& Garon, T.Y. (1997). Changing relations between phonological processing abilities and word-level reading as children develop from beginning to skilled readers: A 5-year longitudinal study. Developmental Psychology, 33, $468-479$. 
Wimmer, H. (1993). Characteristics of developmental dyslexia in a regular writing system. Applied Psycholinguistic, 14, 1- 33.

Wimmer, H. (1996). The early manifestation of developmental dyslexia: evidence from German children. Reading and Writing: An Interdisciplinary Journal, 8, 171-188.

Wimmer, H. (1997). The nonword reading deficit in developmental dyslexia: Evidence from children learning to read German. Journal of Experimental Child Psychology, 61, 80 - 90.

Wimmer, H., Landerl, K., \& Schneider, W. (1994). The role of rhyme awareness in learning to read a regular orthography. British Journal of Developmental Psychology, 12, 469484.

Wimmer, H., \& Goswami, U. (1994). The influences of orthographic Correspondence and reading development: Word recognition in English and German Language. Cognition, 51, 91-103.

Wood, F. B., Flowers, L., \& Grigorenko, E. (2001). On the functional neuroanatomy of fluency or why walking is just as important to reading as talking is. In M. Wolf (Ed.), Dyslexia, fluency, and the brain. Timonium: York Press.

Wolf, M., \& Bowers, P. (1999). The double deficit hypothesis for the developmental dyslexia. Journal of Educational Psychology, 91, 415 - 438.

Wolf, M. \& Katzir-Cohen, T. (2001). Reading fluency and its intervention. Scientific Studies of Reading. 5, 211-238.

Yopp, H.K. (1988). The validity and reliability of phonemic awareness tests._Reading Research Quarterly, 23, 159-177. 
Ziegler, J.C. \& Goswami, U. (2005). Reading acquisition, developmental dyslexia and skilled reading across languages: A psycholinguisitc grain size theory. Psychological Bulletin, $131,3-29$.

Ziegler, J. C. , Perry, C., Wyatt, A.M., Ladner, D.,\& Körne, G.S. (2003). Developmental dyslexia in different languages: Language-specific or universal? Journal of Experimental Child Psychology, 86,169-193. 
Table 1.

Mean (and standard deviation) performance for word and pseudoword reading: accuracy and speed.

\begin{tabular}{lccc}
\hline & Reading & Chronological & Reading Age \\
& Disabled & Age Control & Control \\
\hline Word Reading accuracy & 61.58 & 97.42 & 63.08 \\
& $(5.77)$ & $(3.03)$ & $(4.13)$ \\
Pseudoword Reading accuracy & 51.83 & 97.17 & 53.25 \\
& 6.62 & 3.25 & 4.06 \\
Word reading speed & 1.18 & 0.62 & 0.63 \\
Pseudoword reading speed & 1.26 & 0.74 & $(0.02)$ \\
& $(0.22)$ & $(0.03)$ & 0.75 \\
\hline
\end{tabular}


Table 2

Mean (and standard deviation) performance for the phonological awareness tasks.

\begin{tabular}{|c|c|c|c|}
\hline & Reading disabled & Chronological & Reading Age \\
\hline Task & & Age Control & Control \\
\hline \multirow[t]{2}{*}{ Alliteration Oral } & 95.50 & 99.50 & 99.00 \\
\hline & (8.87) & $(2.24)$ & (3.07) \\
\hline \multirow[t]{2}{*}{ Alliteration Picture } & 97.00 & 100 & 100 \\
\hline & $(8.01)$ & $(.00)$ & $(.00)$ \\
\hline \multirow[t]{2}{*}{ Rhyme } & $75.64^{\mathrm{a}}$ & 99.52 & 99.52 \\
\hline & (22.79) & $(2.13)$ & (3.49) \\
\hline \multirow[t]{2}{*}{ Semi - Spoonerisms } & $81.50^{b}$ & 97.50 & 92 \\
\hline & (22.07) & $(2.13)$ & $(3.49)$ \\
\hline \multirow[t]{2}{*}{ Full- Spoonerisms } & $14.00^{\mathrm{a}}$ & 82 & 72.50 \\
\hline & (18.18) & $(18.23)$ & $(15.52)$ \\
\hline \multirow[t]{2}{*}{ Alliteration fluency } & $5.25^{\mathrm{a}}$ & 7.88 & 8.83 \\
\hline & $(1.58)$ & $(2.12)$ & $(2.06)$ \\
\hline RAN & $\begin{array}{l}38.38^{\mathrm{a}} \\
(7.42)\end{array}$ & $\begin{array}{l}24.54 \\
(4.01)\end{array}$ & $\begin{array}{l}24.59 \\
(4.60)\end{array}$ \\
\hline
\end{tabular}

Notes. a = RD group significantly different from RAC and CAC groups

$\mathrm{b}=\mathrm{RD}$ group significantly different from CAC group 
Table 3

Summary of the hierarchical multiple regression analyses for variables predicting word reading accuracy and speed.

\begin{tabular}{|c|c|c|c|c|c|c|}
\hline \multirow{4}{*}{ Variable } & \multicolumn{4}{|c|}{ Word reading } & \multicolumn{2}{|c|}{ Word reading } \\
\hline & \multicolumn{3}{|c|}{ accuracy } & \multicolumn{3}{|c|}{ speed } \\
\hline & $\mathrm{I}$ & S & $\square$ & B & & \\
\hline & \multicolumn{3}{|c|}{ E B } & \multicolumn{3}{|c|}{ E B } \\
\hline Phonological & $\bar{\varepsilon}$ & 2 & 0 & - & ( & \\
\hline awareness & .08 & .83 & $.47 *$ & 0.05 & .02 & $0.37 *$ \\
\hline \multirow[t]{2}{*}{ RAN } & - & 2 & & 0 & ( & \\
\hline & 1.93 & .83 & 0.11 & .05 & .02 & $.40 *$ \\
\hline
\end{tabular}

Note. Accuracy: $\mathrm{R}^{2}=.309 ;$ Speed: $\mathrm{R}^{2}=.515$ 
Table 4

Mean (and standard deviation) percentage correct scores for reading comprehension and listening comprehension

\begin{tabular}{cccc}
\hline Variable & Reading & Chronological & Reading \\
& Disabled & Age Controls & Age Controls \\
\hline Reading & 87.38 & 96.42 & 94.99 \\
comprehension & $(4.02)$ & $(2.25)$ & $(2.98)$ \\
Listening & 97.49 & 98.09 & 97.14 \\
comprehension & & & \\
& $(1.63)$ & $(1.84)$ & $(1.99)$ \\
\hline
\end{tabular}


Table 5

Summary of the hierarchic regression analysis for variables predicting reading comprehension

\begin{tabular}{llclc}
\hline & Variable & $\underline{\mathrm{B}}$ & $\underline{\mathrm{SE}} \underline{\mathrm{B}}$ & $\square$ \\
\hline Step 1 & & & & \\
& Word reading accuracy & 0.15 & 0.03 & $0.51^{* *}$ \\
Step 2 & & & & \\
& Word reading accuracy & 0.06 & 0.03 & 0.20 \\
& Phonological awareness & 1.71 & 0.79 & $0.34^{*}$ \\
& RAN & -1.30 & 0.74 & -0.26
\end{tabular}

Step 3

Word reading accuracy $\quad 0.05 \quad 0.03 \quad 0.18$

$\begin{array}{llll}\text { Phonological awareness } & 0.99 & 0.75 & 0.20\end{array}$

RAN $\quad-0.45 \quad 0.72 \quad-0.09$

Word reading speed $\quad-0.27 \quad 0.08 \quad-0.43 * *$

Note. $\mathrm{R}^{2}=.26$ for step $2 ; \square \mathrm{R}^{2}=.22$ for $\operatorname{step} 2 ; \mathrm{R}^{2}=.10$ for step 3 (ps $\left.<.001\right)$ 


\section{WORDS}

\section{APENDIX}

\begin{tabular}{|c|c|c|c|}
\hline кó $\tau \alpha$ & $\kappa \varepsilon \varphi \alpha ́ \lambda \imath$ & $\tau \eta \lambda \varepsilon^{\prime} \varphi \omega \vee 0$ & $\kappa \alpha \tau \alpha \gamma \alpha \dot{\lambda} \alpha \nu \mathrm{\alpha} \varsigma$ \\
\hline$\chi \varepsilon \dot{\varepsilon} \rho t$ & 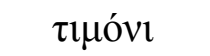 & $\pi \circ \delta \eta ́ \gamma \lambda \alpha \tau o$ & 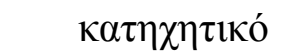 \\
\hline$\mu v^{\prime} \tau \eta$ & $\pi \alpha \lambda \alpha ́ \tau \imath$ & $\chi \varepsilon \lambda \omega \vee \alpha ́ \kappa 1$ & $\pi \alpha \rho \alpha \theta \varepsilon \rho i ́ \zeta \omega$ \\
\hline$\gamma \varepsilon \lambda \omega$ & $\mu о \lambda v ́ \beta t$ & $\rho v \zeta o ́ \gamma \alpha \lambda \mathrm{o}$ & $\xi \varepsilon \rho 1 \zeta \omega \mu \varepsilon^{\prime} \nu o$ \\
\hline$\beta a ́ \zeta o$ & $\mu \varepsilon ́ \tau \omega \pi \mathrm{o}$ & $\sigma \alpha \xi o ́ \varphi \omega v o$ & $\pi \alpha \lambda \imath \kappa \alpha \rho \alpha ́ \kappa \imath$ \\
\hline$\beta \rho v ́ \sigma \eta$ & $\chi \rho \omega ́ \mu \alpha \tau \alpha$ & $\alpha \rho \imath \sigma \tau \varepsilon \rho \alpha ́$ & $\mu v \theta \imath \sigma \tau o ́ \rho \eta \mu \alpha$ \\
\hline$\kappa \rho \alpha \tau \omega ́$ & $\gamma v \omega \rho i ́ \zeta \omega$ & $\varphi \theta \imath v o ́ \pi \omega \rho o$ & $\kappa \tau \eta \nu о \tau \rho о \varphi i ́ \alpha$ \\
\hline$\varphi \tau \varepsilon \rho o ́$ & 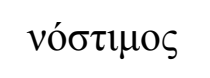 & $\varepsilon \pi \imath \gamma \rho \alpha \varphi \eta ́$ & $v v \chi \tau о \varphi v ́ \lambda \alpha \kappa \alpha \varsigma$ \\
\hline$\pi \rho \omega ́ \tau \alpha$ & $\kappa \rho \varepsilon \beta \alpha ́ \tau \imath$ & $\mu \alpha \theta \eta ́ \tau \rho ı$ & $\varphi \omega \tau о \gamma \rho \alpha \varphi i ́ \zeta \omega$ \\
\hline$\kappa \rho \varepsilon ́ \alpha \varsigma$ & 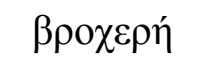 & $\kappa \alpha \lambda \eta \sigma \pi \varepsilon ́ \rho \alpha$ & $\kappa \rho v o \lambda o ́ \gamma \eta \mu \alpha$ \\
\hline$\sigma \kappa v i ́ \pi \alpha$ & 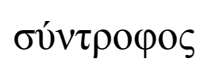 & 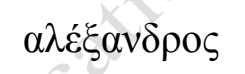 & $\sigma \kappa \lambda \alpha \beta о \pi \alpha ́ \zeta \alpha \rho o$ \\
\hline$\kappa \alpha ́ \sigma \tau \rho о$ & $\mu \pi \lambda \varepsilon \varepsilon^{\prime} \xi \mu \mathrm{o}$ & $\sigma \imath \tau \tau \rho \imath \beta \alpha ́ v \imath$ & 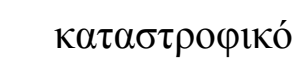 \\
\hline$\kappa \varepsilon ́ v \tau \rho о$ & $\sigma \varphi \rho \alpha \gamma i ́ \delta \alpha$ & $\sigma v \mu \pi \lambda \eta \rho \omega ́ v \omega$ & $\chi о \nu \tau \rho о \kappa \varepsilon ́ \varphi \alpha \lambda \circ \varsigma$ \\
\hline$\mu \pi \rho \alpha ́ \beta o$ & $\varepsilon \kappa \tau \rho о \pi \eta ́$ & $\sigma \varphi \rho \alpha \gamma 1 \sigma \mu \varepsilon ́ v o$ & $\sigma \tau \rho \alpha \beta о \pi \alpha ́ \tau \eta \mu \alpha$ \\
\hline$\alpha ́ \rho \theta \rho o$ &  & 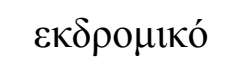 & $\delta \varepsilon v \tau \rho \lambda^{\prime} \beta \alpha{ }^{\prime} \beta$ \\
\hline
\end{tabular}

\section{PSEUDOWORDS}

\begin{tabular}{|c|c|c|c|}
\hline vápo & $\tau \alpha \rho \alpha \chi o ́ s$ & 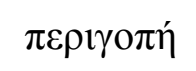 &  \\
\hline кóva & $\pi \alpha \tau \varepsilon \dot{\varepsilon} \lambda \alpha$ & $\tau \eta \lambda \omega ́ \varphi \varepsilon v o$ & $\beta \alpha \rho \varepsilon \lambda o \pi i ́ \delta \imath$ \\
\hline$\mu \alpha ́ \tau \varepsilon$ & $\kappa o \zeta i v a$ & $\pi \alpha \tau \varepsilon \lambda \operatorname{vov}$ & $\gamma \alpha \zeta о \mu \alpha ́ v ı เ \kappa$ \\
\hline$\beta \alpha ́ \xi_{0}$ & $\mu \omega \rho i ́ \gamma \alpha$ & $\sigma \alpha \kappa \varepsilon ́ \varphi \omega \nu o$ & $\kappa v \vee \eta \xi \eta \mu \varepsilon ́ v o$ \\
\hline$\delta \alpha ́ \tau \omega$ &  & $\gamma \alpha \delta о \rho \alpha ́ \kappa 1$ & $\mu v \theta \imath \tau o ́ \rho \eta \mu \alpha$ \\
\hline 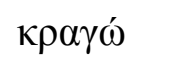 &  & $\pi \alpha v \tau \varepsilon \gamma o ́ \rho l$ & $\tau \rho \alpha \pi \varepsilon \tau i ́ \kappa \alpha \nu o$ \\
\hline$\beta \rho \alpha ́ \xi \omega$ & $\sigma \tau o \lambda i ́ v \imath$ & $\kappa \alpha \rho \varepsilon \kappa \lambda i ́ \mu o$ & $\varphi \omega \tau о \gamma \rho \iota \varphi^{\prime} \zeta \omega$ \\
\hline
\end{tabular}




\begin{tabular}{|c|c|c|c|}
\hline$\gamma \alpha \tau \rho o ́ s$ & 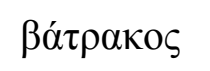 & $\sigma \alpha \kappa \rho \varepsilon ́ \varphi \omega \nu o$ & $\alpha \mu \varphi \imath \gamma о \lambda i ́ \alpha$ \\
\hline 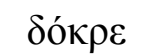 & $\gamma \nu \omega \zeta 1 \kappa o ́$ & $\varepsilon \pi \imath \gamma \rho \alpha \pi \eta ́$ & $v \pi \circ \lambda о \gamma \imath \tau \rho \eta ́ s$ \\
\hline 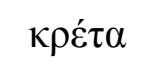 & $\kappa \rho \varepsilon \pi \alpha ́ \tau \imath$ & $\kappa \lambda \varepsilon \circ \pi \omega \dot{ } \lambda \eta \varsigma$ & 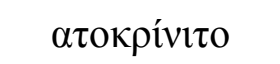 \\
\hline$\sigma \tau \rho \omega ́ \kappa \alpha$ & 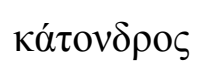 & 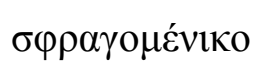 & $\varepsilon \kappa \delta \rho о \mu \alpha \tau \iota \kappa o ́ \varsigma$ \\
\hline$\varphi \varepsilon ́ \rho \theta \rho o$ & $\xi \dot{\varepsilon} \sigma \tau \rho \omega \kappa \varepsilon$ & $\alpha \kappa \delta \rho о \mu 1 \kappa o ́$ & $\varphi \alpha \sigma \kappa \lambda \circ \varphi \omega v i \kappa \alpha ́$ \\
\hline$\kappa \varepsilon ́ \mu \pi \rho o$ & 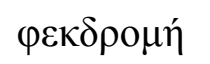 & $\varepsilon \pi \imath \sigma \tau \rho \varepsilon ́ \chi \omega$ & $\alpha \nu \theta \rho \omega \pi \alpha \sigma 1 \kappa o ́$ \\
\hline$\varphi \varepsilon ́ \sigma \tau \rho \alpha$ & $\alpha \kappa \tau \rho о \beta \eta ́$ & 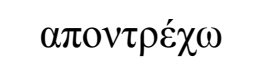 & $\alpha \pi \alpha v \alpha \sigma \tau \rho о \pi \eta ́$ \\
\hline$\xi{ }^{\alpha} v \delta \rho \eta$ & $\pi \alpha ́ v \theta \rho о \pi о \varsigma$ & $\sigma \tau \rho о \gamma v \dot{\lambda} \imath \iota \mu \alpha$ & 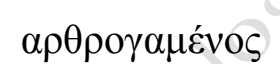 \\
\hline
\end{tabular}

